\title{
Correlation of Crown Rump Length with Foetal Age In Jharkhand Population
}

\author{
Dr.Dharmendra Kumar ${ }^{1}$ Dr.Ashok Kumar Dubey ${ }^{2}$ \\ ${ }^{1,2}$ Associate Professor, Department of Anatomy, Rajendra Institute of Medical Sciences , Ranchi
}

\begin{abstract}
Introduction: Crown-rump length $(C R L)$ is the measurement of the length of human embryo and fetuses from the top of the head (crown) to the bottom of the buttocks (rump).

Material and Method: Foetuses of different age groups were collected from Department of Obstetrics \& Gynaecology and from different private nursing homes in Ranchi and kept in $10 \%$ formalin for 10 days . On $10^{\text {th }}$ day the CRL was measured using a measuring tape from vertex to buttock, maintaining the hyper flexed attitude of foetus. The data was analysed by using regression analysis and compared with Statistical data of study named Intergrowth 21.

Result: This study shows that CRL is statistically highly significant in prediction of foetal age.

Conclusion: Dating of pregnancy should be done on multi facet basis based on CRL, LMP and analysis of placental membranes.
\end{abstract}

\section{Introduction}

Crown-rump length (CRL) is the measurement of the length of human embryo and fetuses from the top of the head (crown) to the bottom of the buttocks (rump). It is typically determined from ultrasound imaging and can be used to estimate gestational age and expected date of delivery.

Fetal ultrasound scanning is considered vital for routine antenatal care with first trimester scans recommended for accurate estimation of gestational age (GA). A reliable estimate of gestational age is key information underpinning clinical care and allows estimation of expected date of delivery. Fetal crown-rump length (CRL) is recommended over last menstrual period for estimating GA when measured in early pregnancy The National Institute for Health and Care Excellence (NICE) Guideline for Routine Antenatal Care (2008) and International Society of Ultrasound in Obstetrics and Gynaecology (ISUOG) recommend that all pregnant women should be offered an early US examination to date pregnancies. It is stated that ideally this should be performed by the measurement of CRL between 10 and $13^{+6}$ weeks which can reduce the need for induction of labour after 41 weeks of gestation. Although there is always a margin of error in USG-based estimation, this error is relatively small compared to LMP-based estimations.

Recent evidence has indicated that CRL growth (and thus the approximation of gestational age) may be influenced by maternal factors such as age, smoking, and folic acid intake. Early in pregnancy it is accurate within +/- 4 days but later in pregnancy due to different growth rates, the accuracy is less. In that situation, other parameters can be used in addition to CRL. The length of the umbilical cord is approximately equal to the CRL throughout pregnancy. The purpose of this study is to collect, analyse and evaluate the data on CRL , compare it with data on similar studies and finally establish a practical baseline information for population of Jharkhand.

\section{Materials And Methodology}

The present work was carried out at Department of Anatomy, Rajendra Institute of Medical Sciences, Ranchi over a period of 1 year. Workstation consisted of 68 foetuses ,jar, 10\% formalin, rectangular tray, scalpel, BP blade, fine toothed forceps, fine plane forceps, Mitzenbaum scissors, measuring tape. Linen, marker pen, camera and gloves.Foetuses of different age groups were collected from Department of Obstetrics \& Gynaecology and from different private nursing homes in Ranchi. A total of 68 foetuses were collected out of which 50 were products of MTP and 18 from labour room. Foetuses from labour room were those that died due to certain problems during delivery and traumatic accidents of mother. Mothers were otherwise healthy with no obstetric or medical complications. Foetuses with anatomical deformity were excluded from study. Inclusion criteria for foetuses was from those mothers having good menstrual dating, singleton pregnancy,per abdomen size of foetues tallied with LMP , no medical or obstetric complications and mothers who were native of Jharkhand.Foetuses were kept in 10\% formalin for 10 days. On $10^{\text {th }}$ day the CRL was measured using a measuring tape from vertex to buttock, maintaining the hyper flexed attitude of foetus. Gestational age for each foetus was calculated from first day of last menstrual cycle and confirmed by obstetric examination 


\section{Results}

Statistical analysis :-The data was analysed by using regression analysis with and compared with Statistical data of study named INTERGROWTH 21 . The data is presented in form of tables and graphs. In the present study CRL was found to be statistically highly significant in prediction of foetal age with $r$ value of 0.979 and $t$ value of 39.81 at $5 \%$ level of significance and $\mathrm{p}$ value $<0.01$

\begin{tabular}{|l|l|l|}
\hline WEEKS & INTERGROWTH 21 & PRESENT STUDY \\
\hline $12-16$ & $6.1-10.0$ & $11.5-15.6$ \\
\hline $16-20$ & $10.1-15.0$ & $17.0-22.5$ \\
\hline $20-24$ & $15.1-20.0$ & $23.0-26.5$ \\
\hline $24-28$ & $20.1-26.0$ & $27.0-30.5$ \\
\hline $28-32$ & $26.1-32.0$ & $30.0-34.0$ \\
\hline $32-36$ & $32.1-39.0$ & $34.1-37.0$ \\
\hline $36-40$ & 39.1 above & $38.0-38.2$ \\
\hline
\end{tabular}

\begin{tabular}{|l|l|l|}
\hline Gestational Age & Mean Crl & Standard Deviation \\
\hline $12-16 \mathrm{Wk}$ & 14.5 & 1.77 \\
\hline $16-20 \mathrm{Wk}$ & 20.2 & 1.86 \\
\hline $20-24 \mathrm{Wk}$ & 25.0 & 1.10 \\
\hline $24-28 \mathrm{Wk}$ & 28.6 & 1.58 \\
\hline $28-32 \mathrm{Wk}$ & 31.4 & 1.73 \\
\hline $32-36 \mathrm{wk}$ & 35.1 & 1.46 \\
\hline $36-40 \mathrm{Wk}$ & 38.2 & 0.20 \\
\hline
\end{tabular}

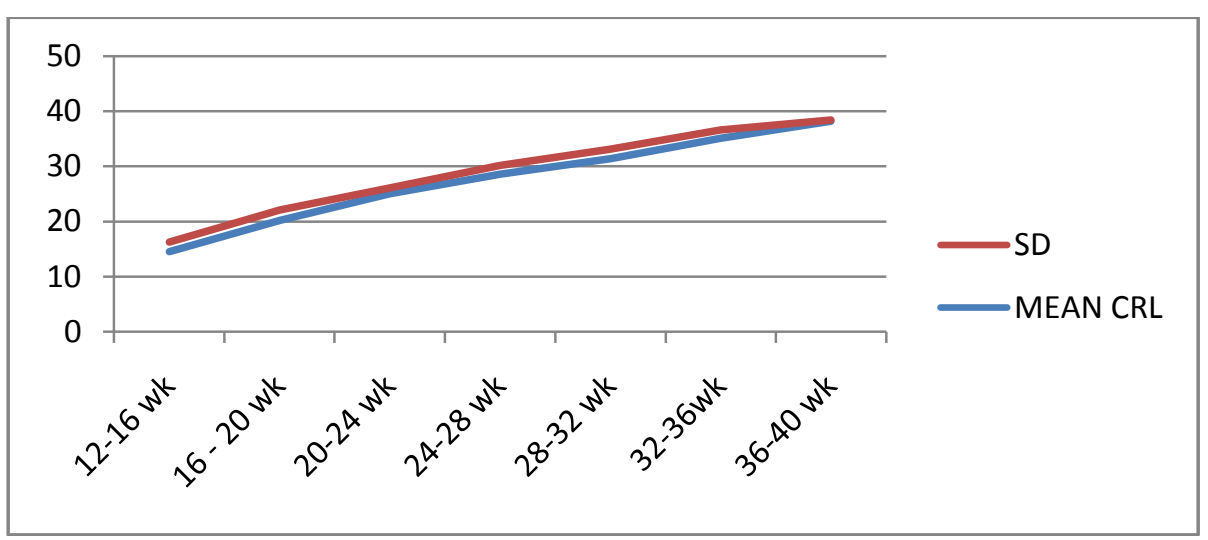

IV. Discussion

This study shows that CRL is statistically highly significant in prediction of foetal age . There is some degree of variation but no significant variation between foetuses from population of Jharkhand and the global study conducted in INTERGROWTH 21. The difference between gestational age by USG and anatomic measurements varied between 4.7 days or less in $95 \%$ cases (Robinson H.P )

There is wide agreement that CRL is the best measure for assessing gestational age, certainly up to 14 weeks GA, since LMP is affected by both random error and systematic tendency to overstate the duration of gestation, biological variability and errors of the method including recall bias, digit preference, and additional bleeding after conception. Ultrasound-based methods measure fetal size and use reliable LMP-based formulas (of which many are in use) to estimate gestational age; however this assumes no biological variability as all foetuses of a given size are estimated to have the same gestational age. However, biological variability exists and this is compounded by variability due to measurement error due to equipment and observer.

\section{Conclusion}

Dating of pregnancy should be done on multi facet basis based on CRL, LMP and analysis of placental membranes. Standard equations used for estimating GA based on CRL shows a minor degree of variation due to genetic and biological variability and past medical and obstetric history of mother. 


\section{Refrences}

[1]. ISUOG. Practice guidelines: performance of first-trimester fetal ultrasound scan. Ultrasound Obstet Gynecol. 2013;13(1):102-113.

[2]. Verburg BO, Steegers EAP, De Ridder M, Snijders RJM, Smith E, Hofman A, Moll HA, Jaddoe VWV, Witteman JCM. New charts for ultrasound dating of pregnancy and assessment of fetal growth: longitudinal data from a population-based cohort study. Ultrasound Obstet Gynecol. 2008;13(4):388-396. doi: 10.1002/uog.

[3]. Treloar A, Behn BG, Cowan DW. Analysis of gestational interval. Am J Obstet Gynecol. 1967;13:34-45.

[4]. Campbell S. The prediction of fetal maturity by ultrasonic measurement of the biparietal diameter. BJOG. 1969;13(7):603-609. doi: 10.1111/j.1471-0528.1969.tb06146.x.

[5]. Campbell S, Warsof SL, Little D, Cooper DJ. Routine ultrasound screening for the prediction of gestational age. Obstet Gynecol. 1985;13(5):613-620

[6]. Waldenström U, Axelsson O, Nilsson S. A comparison of the ability of a sonographically measured biparietal diameter and the last menstrual period to predict the spontaneous onset of labor. Obstet Gynecol. 1990;13(3 Pt 1):336-33

[7]. Institute of Obstetricians and Gynaecologists; Royal College of Physicians of Ireland; Directorate of Quality and Clinical Care: HSE. Ultrasound diagnosis of early pregnancy miscarriage. Clin Pract Guidel. 2010. pp. 4-7. Version 1. Guideline 1.

[8]. Haglund B. Birthweight distributions by gestational age: comparison of LMP-based and ultrasound-based estimates of gestational age using data from the Swedish Birth Registry. Paediatr Perinat Epidemiol. 2007;13:72-78. doi: 10.1111/j.1365-3016.2007.00863.x.

[9]. Grange G, Pannier E, Goffinet F, Cabrol D, Zorn J-R. Dating biometry during the first trimester: accuracy of an every-day practice. Eur J Obstet Gynecol Reprod Biol. 2000;13(1):61-64. doi: 10.1016/S0301-2115(99)00127-X. 